\title{
Comparison of Corneal Biomechanical Properties of Physiological Macrodiscs and Glaucomatous Macrodiscs
}

\author{
Funda Ebru Onmez, Ayse Cigdem Altan, Banu Satana, Berna Basarir, Isil Pasaoglu, Muhittin Taskapili \\ University of Health Sciences Beyoglu Eye Training and Research Hospital, Istanbul, Turkey
}

\begin{abstract}
Objectives: This study was designed to compare optic nerve head $(\mathrm{ONH})$ parameters and corneal biomechanical properties of healthy and glaucomatous macrodiscs.

Methods: This cross-sectional study included total of 234 eyes, of which 92 served as normal controls, 92 had healthy macrodiscs, and 50 had glaucomatous macrodiscs. Measurement of $\mathrm{ONH}$ parameters in all $\mathrm{p}\urcorner$ atients was performed using optic coherence tomography $(\mathrm{OCT})$. Corneal hysteresis $(\mathrm{CH})$ was measured in each patient using Ocular Response Analyzer (ORA; Reichert, Inc., Depew, NY, USA). Central corneal thickness (CCT) was determined by ultrasonic pachymetry. All OCT and ORA parameters of healthy and glaucomatous macrodiscs were compared.

Results: Optic disc area of healthy macrodiscs and glaucomatous macrodiscs was similar, and larger than observed in control group $(p=0.70, p=0.000$ I, respectively). Rim area was significantly thinner in glaucoma group than healthy macrodisc group or control group. $(p=0.000 \mathrm{I}, \mathrm{p}=0.022$, respectively) Mean cup area of glaucomatous discs was larger than healthy macrodiscs $(p=0.00 \mathrm{I})$. Cup/disc $(C / D)$ area ratio, and horizontal and vertical $C / D$ ratios were higher in glaucoma group than healthy macrodisc group $(p=0.002, p=0.002, p=0.018$, respectively) ORA analyses revealed that $\mathrm{CH}$ of glaucoma patients was lower than that of healthy macrodisc or control group $(p=0.048, p=0.035$, respectively), whereas, mean $\mathrm{CH}$ of macrodisc group was similar to that of control group $(p=0.988)$. Mean CCT of macrodisc group was higher than that observed in control or glaucoma patients $(p=0.015, p=0.045)$.

Conclusion: It was concluded that OCT analyses can help differentiate healthy macrodiscs from glaucomatous discs. $\mathrm{CH}$ and corneal thickness measurements of healthy macrodiscs are greater than those of glaucomatous optic discs.
\end{abstract}

Keywords: Glaucoma, large optic disc, macrodisc, ocular response analyzer, optic nerve head analysis.

\section{Introduction}

Glaucoma is chronic optic neuropathy that leads to progressive injury to the optic nerve and retinal nerve fiber layer (RNFL). Elevated intraocular pressure (IOP) is the bestknown risk factor for glaucoma. Recent studies revealed that corneal biomechanical factors affect IOP measurements and ocular effects of IOP (I). The Ocular Response Analyzer (ORA) (Reichert Inc., Depew, NY, USA) evaluates biomechanical properties of the cornea in situ. Corneal hysteresis $(\mathrm{CH})$ measurement obtained using ORA demonstrates cor- nea's ability to dampen and buffer fluctuations in IOP (2).

It has been suggested that eyes with greater $\mathrm{CH}$ tend to have more capacity to buffer increases in IOP, providing a protective property $(\mathrm{I}, 3)$. Low $\mathrm{CH}$ might increase risk for developing glaucomatous optic neuropathy, possibly due to reduced capacity of the eyewall to buffer IOP spikes $(3,4)$. In addition, it has been proposed that lower $\mathrm{CH}$ might influence both glaucoma progression and severity (5-7).

Clinical estimation of vertical cup/disc ratio (C/D) remains the most frequently performed assessment of the optic disc in diagnosis and follow-up of glaucoma. C/D ratio is

Address for correspondence: Funda Ebru Onmez, MD. Beyoglu Goz Egitim ve Arastirma Hastanesi, Bereketzade Cami Sokak, 34421 Beyoglu, Istanbul, Turkey

Phone: +90 2122515900 E-mail: ebru.funda@gmail.com

Submitted Date: January 28, 2017 Accepted Date: March 28, 2017 Available Online Date: May 04, 2017

${ }^{\odot}$ Copyright 2017 by Beyoglu Eye Training and Research Hospital - Available online at www.beyoglueye.com 
physiologically related to optic disc size (8-10). As large optic nerve heads (ONHs) have large cups, they can be misdiagnosed and treated as glaucoma. Therefore, differentiation of $\mathrm{ONH}$ parameters between normal-sized discs and macrodiscs is extremely important for differential diagnosis of healthy macrodisc from glaucomatous optic neuropathy. Our previous study revealed that macrodiscs have larger cup area, horizontal and vertical C/D ratio, and C/D ratio compared with normal-sized discs using optical coherence tomography (OCT). Moreover, RNFL thicknesses, rim area, and visual field (VF) indices (mean deviation [MD], pattern standard deviation [PSD]) of macrodiscs were similar to those of normal eyes (II).

The aim of this study was to assess whether biomechanical properties of corneal tissue of the eye in healthy patients with macrodics are different from those of glaucoma patients with macrodiscs.

\section{Methods}

Cross-sectional, comparative study was conducted. Before being included in the study, each individual was informed of its purpose and provided written consent to participate. All participants ranged in age from 40 to 70 years. All tested eyes had best corrected visual acuity above $20 / 25$, spherical refractive error within \pm 2.0 diopters, cylindrical error within \pm 2.0 diopters, and intraocular pressure $\leq 2 \mathrm{I} \mathrm{mmHg}$.

In this study, we defined macrodiscs as larger than 2.80 $\mathrm{mm}^{2}$. Normal disc size was defined as disc area between I.4 and $2.80 \mathrm{~mm}^{2}$ (II). According to this definition, 3 groups were formed: normal control patients, patients with healthy macrodiscs, and patients with glaucomatous macrodiscs.

Normal control patients and those with healthy macrodiscs were patients with no remarkable medical or ocular history who came to ophthalmology clinic for regular eye examination. They underwent a complete ophthalmic evaluation, including past medical history, IOP measurement using Goldmann applanation tonometry, gonioscopy, VF testing, central corneal thickness (CCT) measurement with corneal ultrasound pachymeter, undilated and dilated biomicroscopy, and dilated fundus examination. Ophthalmic evaluation, ORA measurement, VF testing, and OCT imaging were all performed within I month.

Glaucomatous participants with macrodiscs had already been diagnosed and presented for antiglaucoma treatment; they underwent same ophthalmological examinations as healthy individuals to confirm diagnosis. Patients with angle-closure, normal-tension, pigmentary, inflammatory, or aphakic glaucoma, and patients who had undergone glaucoma surgery, were excluded from the study.

ORA was used to measure $\mathrm{CH}$ and obtain 3 other output variables: corneal resistance factor (CRF), corneal-compen- sated IOP (IOPcc), and Goldmann-correlated IOP (IOPg). For this study, 3 measurements were performed for each eye, and average was accepted as final value used for statistical analysis. Readings from instrument required consistent and clean raw signal morphology (well-defined raw signal peaks with repeatable characteristics for multiple measurements).

All optic disc and RNFL measurements were performed using fast optic disc scanning protocol and automated $\mathrm{ONH}$ analysis using Stratus OCT device and version 3.0 software (Carl Zeiss Meditec, Inc., Dublin, CA, USA). Maximum of 2 $\mathrm{ONH}$ scans of each patient were obtained and better of 2 scans was chosen for interpretation. Fast RNFL algorithm was used to measure RNFL thickness with Stratus OCT. Three scan images were obtained from each participant, with each image consisting of $256 \mathrm{~A}$-scans along a 3.4-mm-diameter ring around the optic disc. These values were averaged to yield 12 clock-hour thicknesses, 4 quadrant thicknesses, and global average RNFL thickness measurement.

Default axial length and refraction for optic disc measurement in every OCT scan were set to $24.46 \mathrm{~mm}$ and $0 \mathrm{D}$, respectively. Therefore, exact disc size in an eye with axial length other than $24.46 \mathrm{~mm}$ and/or refraction $<0 \mathrm{D}$ is different from printout values and manual correction of optic disc measurements is necessary. In order to correct axial length-related ocular magnification, Littmann formula $(\mathrm{t}=\mathrm{p} \cdot \mathrm{q} \cdot \mathrm{s})$, as modified by Bennet and later adopted by Leung et al. and Kang et al. was applied (12-15). In this formula, $t$ is actual fundus dimension, $s$ is measurement on OCT, $P$ is magnification factor related to imaging system, and $q$ is magnification factor related to the eye. Factor $\mathrm{p}$ is instrument-dependent and remains a constant in telecentric imaging system; for Stratus OCT, this figure is 3.382 . Ocular magnification factor $\mathrm{q}$ of the eye can be determined with formula $q=0.01306$. (axial length -1.82 ) (14). Therefore, given a value, $s$, obtained with $O C T$, the real size of RNFL peripapillary scan circle can be determined by means of the formula $\mathrm{t}=3.382 \cdot 0.01306 \cdot($ axial length -1.82 ) $\cdot \mathrm{s}$. Because Littmann formula refers to linear magnification, for this study, equation was modified to $t^{2}=p^{2} \cdot q^{2} \cdot s^{2}$ for area magnification, according to suggestion of Leung et al. (16).

Patients with significant ocular disorder, history of intraocular surgery, or systemic disease with possible ocular involvement, such as diabetes mellitus, were excluded from the study. OCT scans with signal strength of less than 6 were also excluded. All participants had reliable (fixation loss, false-positive, and false-negative error less than $10 \%$ ), and normal [absence of all 3 of Anderson and Patella's criteria (15)] Humphrey 30-2 Swedish Interactive Threshold Algorithm-standard testing. One eye of each participant was enrolled. If both eyes met inclusion criteria, randomization was performed. 
Table I. Demographic and clinical characteristics of the study groups

\begin{tabular}{|c|c|c|c|c|}
\hline & $\begin{array}{l}\text { Healthy macrodiscs } \\
\qquad(n=92)\end{array}$ & $\begin{array}{l}\text { Glaucomatous macrodiscs } \\
\qquad(n=50)\end{array}$ & $\begin{array}{l}\text { Control group } \\
\qquad(n=92)\end{array}$ & $\mathbf{p}$ \\
\hline & Mean士SD & Mean $\pm S D$ & Mean $\pm S D$ & \\
\hline Male/female, n (\%) & $52(56) / 40(44)$ & $27(54) / 23(46)$ & $42(45.7) / 50(54.3)$ & 0.15 \\
\hline Disc area $\left(\mathrm{mm}^{2}\right)$ & $3.12 \pm 0.23$ & $3.18 \pm 0.28$ & $2.40 \pm 0.28$ & $<0.001$ \\
\hline PSD (db) & $1.89 \pm 0.6 \mid$ & $2.60 \pm 1.52$ & $1.96 \pm 1.06$ & $<0.00$ I \\
\hline $\mathrm{CCT}(\mu \mathrm{m})$ & $564.8 \pm 34.2$ & $550.0 \pm 35.8$ & $553.0 \pm 33.2$ & 0.009 \\
\hline Axial length (mm) & $23.1 \pm 0.73$ & $23.3 \pm 0.84$ & $23.6 \pm 0.75$ & 0.36 \\
\hline
\end{tabular}

\section{Statistical Analysis}

All statistical analyses were performed with SPSS software (SPSS for Windows, Version 15.0; SPSS Inc., Chicago, IL, USA). Categorical variables were compared using $\chi^{2}$ analysis, and continuous variables with normal distributions were compared with one-way analysis of variance test. Kolmogorov-Smirnov nonparametric test was used to evaluate normal distribution of numerical data. Results of measurements were expressed as mean $\pm \mathrm{SD}$. Pearson's correlation coefficient analyses were performed to evaluate relationship between $\mathrm{CH}$ and other parameters. $\mathrm{P}<0.05$ was considered statistically significant.

\section{Results}

Table I is a summary of baseline characteristics of normal eyes, healthy macrodiscs, and glaucomatous macrodiscs. Study included total of 234 eyes of 234 patients, of whom 92 participants served as normal controls, 92 had glaucoma, and 50 had healthy macrodiscs.

Optic disc area of healthy macrodiscs and glaucomatous eyes was similar, and larger than that of control group $(p=0.70, p=0.000 \mathrm{I}$, respectively). Rim area was significantly thinner in glaucoma group than healthy macrodisc group and control group ( $p=0.0001, p=0.022$, respectively). Cup area was determined to be significantly smaller in control group than other groups, and mean cup area of glaucomatous discs was larger than seen in healthy macrodiscs $(p=0.0001$, $p=0.00 \mathrm{I}$, respectively). $C / D$ area ratio, and horizontal and vertical $C / D$ ratios were higher in glaucoma group than in healthy macrodisc group $(p=0.002, p=0.002, p=0.018$, respectively) (Table 2).

ORA analyses revealed that mean IOPg values were similar between study groups $(p=0.19)$, but mean IOPcc of glaucoma group was significantly higher than seen in healthy macrodisc or control group $(p=0.024, p=0.003$, respectively). $\mathrm{CH}$ of glaucoma patients was lower than that of healthy macrodisc group or control group $(p=0.048, p=0.035$, respectively), whereas, mean $\mathrm{CH}$ of macrodisc group was similar to that of control group $(p=0.988)$. Mean CCT of healthy macrodisc group was found to be higher than that of control group or glaucoma group $(p=0.015, p=0.045)$ (Table 3).

There was no statistically significant correlation between age and $\mathrm{CH}$ in control or healthy macrodisc group $(p=0.229)$; however, significant negative correlation was determined in glaucoma group $(p=0.004)$.

MD was similar between the 3 groups. There was significant positive correlation between $\mathrm{MD}$ and $\mathrm{CH}$ in glaucoma group. PSD was significantly higher in glaucoma group $(p=0.000 \mathrm{I})$. Correlation analysis revealed that PSD was not related to $\mathrm{CH}$ in control patients or glaucoma group; however, there was positive correlation between $\mathrm{CH}$ and PSD in healthy macrodisc group $(p=0.026)$.

\section{Discussion}

Present study was designed with primary objective of evaluating and comparing $\mathrm{CH}$ and other ORA parameters of healthy macrodiscs, glaucomatous macrodiscs, and normal-sized discs. To the best of our knowledge, this is first study to investigate corneal biomechanical properties of macrodiscs.

We found that $\mathrm{CH}$ was significantly lower in glaucomatous macrodiscs and that IOPcc was significantly higher in this group. We also determined that healthy macrodiscs had thicker CCT than glaucomatous macrodiscs or control group.

As large $\mathrm{ONH}$ have large cups, they can be misdiagnosed and treated as glaucomatous. Therefore, differentiation of $\mathrm{ONH}$ parameters of normal and macrodiscs is extremely important for differential diagnosis of healthy macrodisc from glaucomatous optic neuropathy. Our study revealed that glaucomatous eyes had lower rim area value than healthy macrodiscs, as well as higher $C / D$ ratio and horizontal and 
Table 2. Comparison of optical coherence tomography parameters (magnification corrected) between healthy macrodiscs, glaucomatous macrodiscs, and normal-sized discs

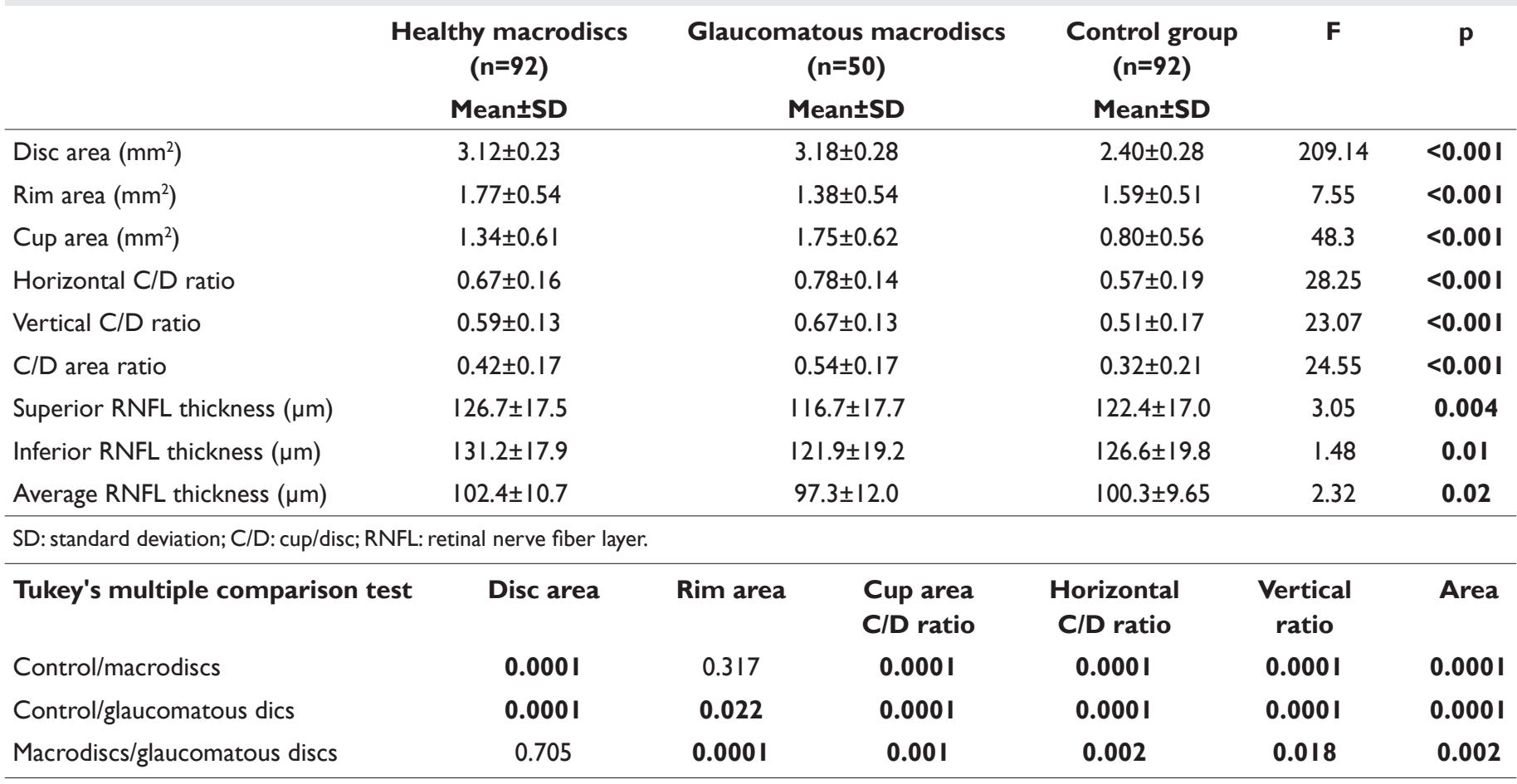

Table 3. Comparison of Ocular Response Analyzer measurements of healthy macrodiscs, glaucomatous macrodiscs, and control group

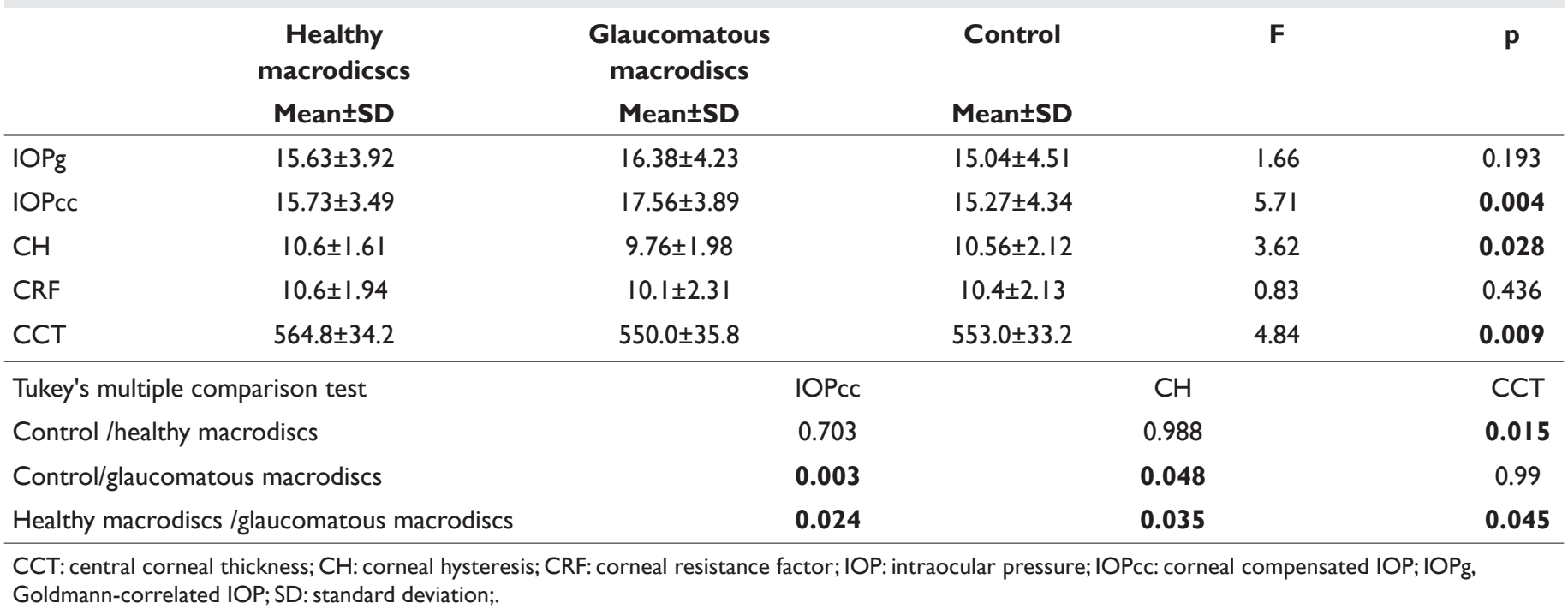

vertical C/D ratio than seen in healthy macrodiscs.

$\mathrm{CH}$ is biomechanical property that can provide insight into normal development and pathological changes of the cornea. As Luce et al. reported, $\mathrm{CH}$ is not correlated with corneal curvature, astigmatism, VA, or axial length (I7).

$\mathrm{CH}$ represents a dynamic resistance component of the cornea (18). Distensible ocular structures may be associated with progression of glaucomatous lesions and biomechanical properties of the cornea may reveal weakness in the lamina cribrosa. As previously reported, lower $\mathrm{CH}$ has been associated with progressive worsening of VF in patients with glaucoma. Bochmann et al. compared $\mathrm{CH}$ measurements in glaucoma patients and patients with acquired pit of the optic nerve head (APON). The latter condition mainly occurs in normotensive glaucoma and is associated with higher risk of progressive optic disc damage (19). They found that $\mathrm{CH}$ 
was significantly lower in APON patients than in glaucoma patients (20). This finding also shows that lower $\mathrm{CH}$ could be marker for possible susceptibility of the optic nerve to glaucomatous damage, independent of CCT. As such, our study showed that $\mathrm{CH}$ of these healthy macrodiscs was similar to that of control group. Glaucomatous eyes with large disc area had lower $\mathrm{CH}$ than healthy macrodiscs.

Large discs have large total lamina cribrosa area and more lamina pores than small discs. These pores allow more space for nerve fibers to travel through, and therefore, they reduce risk of compression to the optic nerve axons (2I). On the other hand, pressure differential across the lamina cribrosa can produce an increased deformation and displacement of the central tissue in macrodiscs, leading to greater glaucoma susceptibility in these eyes $(22,23)$. Burgoyne et al. suggested that mechanical failure of the connective tissue of the lamina cribrosa underlies glaucomatous cupping. Therefore, large discs may be more susceptible to pressure damage, as per Laplace's law (24). Burk et al. concluded that statistically normal IOP readings should not be considered protection against future glaucomatous damage, especially in $\mathrm{ONH}$ with increased cupping and large disc areas (25). Hence, we can suggest that eyes with large optic disc area may be susceptible to glaucomatous damage, but high $\mathrm{CH}$ and corneal thickness can provide protection.

Weizer et al. demonstrated that CCT diminished after mean follow-up of 8 years, and this reduction was more pronounced in glaucomatous patients than in healthy subjects. However, exact mechanism of this reduction in glaucoma patients has not been explained. In this study, we found negative correlation between age and CCT only in glaucoma group (26).

Limitation of this study was that our glaucoma patients had been taking glaucoma medications, including prostaglandins, for significant length of time. There is chance that this may have affected ORA measurements. Prospective studies should be carried out to investigate this hypothesis.

In conclusion, macrodisc may have macrocup and should not be misdiagnosed as glaucoma. Present study has shown that healthy macrodiscs can be differentiated from glaucomatous discs using OCT parameters of rim area, cup area, $C / D$ area ratio, and vertical and horizontal C/D ratios. We suggest that macrodiscs may be susceptible to glaucomatous damage due to mechanical failure of lamina cribrosa, but high level of $\mathrm{CH}$ and corneal thickness can provide protection against this damage.

\section{Disclosures}

Peer-review: Externally peer-reviewed.

Conflict of Interest: None declared.

Authorship Contributions: Involved in design and conduct of the study (FEO, BS, CA,BB, IBP, MT); preparation and review of the study (FEO, BS, CA,MT); data collection (FEO, CA, BB, IP); and statistical analysis (FEO, IP, BB).

\section{References}

I. Sullivan-Mee M, Billingsley SC, Patel AD, Halverson KD, Alldredge BR, Qualls C. Ocular Response Analyzer in subjects with and without glaucoma. Optom Vis Sci 2008;85:463-70.

2. Pensyl D, Sullivan-Mee M, Torres-Monte M, Halverson K, Qualls C. Combining corneal hysteresis with central corneal thickness and intraocular pressure for glaucoma risk assessment. Eye (Lond) 201 2;26:1349-56. [CrossRef]

3. Johnson CS, Mian SI, Moroi S, Epstein D, Izatt J, Afshari NA. Role of corneal elasticity in damping of intraocular pressure. Invest Ophthalmol Vis Sci 2007;48:2540-4. [CrossRef]

4. Liu J, He X. Corneal stiffness affects IOP elevation during rapid volume change in the eye. Invest Ophthalmol Vis Sci 2009;50:2224-9. [CrossRef]

5. Congdon NG, Broman AT, Bandeen-Roche K, Grover D, Quigley HA. Central corneal thickness and corneal hysteresis associated with glaucoma damage. Am J Ophthalmol 2006; |41:86875. [CrossRef]

6. De Moraes CV, Hill V, Tello C, Liebmann JM, Ritch R. Lower corneal hysteresis is associated with more rapid glaucomatous visual field progression. J Glaucoma 2012;21:209-13. [CrossRef]

7. Anand A, De Moraes CG, Teng CC, Tello C, Liebmann JM, Ritch R. Corneal hysteresis and visual field asymmetry in open angle glaucoma. Invest Ophthalmol Vis Sci 2010;51:65I4-8.

8. Crowston JG, Hopley CR, Healey PR, Lee A, Mitchell P; Blue Mountains Eye Study. The effect of optic disc diameter on vertical cup to disc ratio percentiles in a population based cohort: the Blue Mountains Eye Study. Br J Ophthalmol 2004;88:76670. [CrossRef]

9. Garway-Heath DF, Ruben ST, Viswanathan A, Hitchings RA. Vertical cup/disc ratio in relation to optic disc size: its value in the assessment of the glaucoma suspect. $\mathrm{Br} J$ Ophthalmol 1998;82: I I 18-24. [CrossRef]

10. Jonas JB, Gusek GC, Naumann GO. Optic disc, cup and neuroretinal rim size, configuration and correlations in normal eyes. Invest Ophthalmol Vis Sci 1988;29:1 I5I-8.

II. Onmez FE, Satana B, Altan C, Basarir B, Demirok A. A comparison of optic nerve head topographic measurements by Stratus OCT in patients with macrodiscs and normal-sized healthy discs. J Glaucoma 2014;23:e I52-6. [CrossRef]

12. Leung CK, Mohamed S, Leung KS, Cheung CY, Chan SL, Cheng DK, et al. Retinal nerve fiber layer measurements in myopia: An optical coherence tomography study. Invest Ophthalmol Vis Sci 2006;47:5I7I-6. [CrossRef]

13. Littmann H. Determination of the real size of an object on the fundus of the living eye. Klin Monbl Augenheilkd 1982;180:286-9.

14. Bennett AG, Rudnicka AR, Edgar DF. Improvements on Littmann's method of determining the size of retinal features 
by fundus photography. Graefes Arch Clin Exp Ophthalmol 1994;232:36I-7. [CrossRef]

I5. Kang SH, Hong SW, Im SK, Lee SH, Ahn MD. Effect of myopia on the thickness of the retinal nerve fiber layer measured by Cirrus HD optical coherence tomography. Invest Ophthalmol Vis Sci 2010;5I:4075-83. [CrossRef]

16. Leung CK, Cheng AC, Chong KK, Leung KS, Mohamed S, Lau $\mathrm{CS}$, et al. Optic disc measurements in myopia with optical coherence tomography and confocal scanning laser ophthalmoscopy. Invest Ophthalmol Vis Sci 2007;48:3 I78-83. [CrossRef]

17. Luce DA. Determining in vivo biomechanical properties of the cornea with an ocular response analyzer. J Cataract Refract Surg 2005;3 I: I 56-62. [CrossRef]

18. Congdon NG, Broman AT, Bandeen-Roche K, Grover D, Quigley HA. Central corneal thickness and corneal hysteresis associated with glaucoma damage. Am J Ophthalmol 2006; |41:86875. [CrossRef]

19. Ugurlu S, Weitzman M, Nduaguba C, Caprioli J. Acquired pit of the optic nerve: a risk factor for progression of glaucoma. Am J Ophthalmol 1998; 125:457-64. [CrossRef]

20. Bochmann F, Ang GS, Azuara-Blanco A. Lower corneal hysteresis in glaucoma patients with acquired pit of the optic nerve
(APON). Graefes Arch Clin Exp Ophthalmol 2008;246:735-8. 2I. Hoffmann EM, Zangwill LM, Crowston JG, Weinreb RN. Optic disk size and glaucoma. Surv Ophthalmol 2007;52:32-49. [CrossRef]

22. Jonas JB, Budde WM, Panda-Jonas S. Ophthalmoscopic evaluation of the optic nerve head. Surv Ophthalmol 1999;43:293320. [CrossRef]

23. Jonas JB, Mardin CY, Schlötzer-Schrehardt U, Naumann GO. Morphometry of the human lamina cribrosa surface. Invest Ophthalmol Vis Sci 1991;32:40I-5.

24. Burgoyne CF, Downs JC, Bellezza AJ, Suh JK, Hart RT. The optic nerve head as a biomechanical structure: a new paradigm for understanding the role of IOP-related stress and strain in the pathophysiology of glaucomatous optic nerve head damage. Prog Retin Eye Res 2005;24:39-73. [CrossRef]

25. Burk RO, Rohrschneider K, Noack H, Völcker HE. Are large optic nerve heads susceptible to glaucomatous damage at normal intraocular pressure? A three-dimensional study by laser scanning tomography. Graefes Arch Clin Exp Ophthalmol 1992;230:552-60. [CrossRef]

26. Weizer JS, Stinnett SS, Herndon LW. Longitudinal changes in central corneal thickness and their relation to glaucoma status: an 8 year follow up study. Br J Ophthalmol 2006;90:732-6. 